
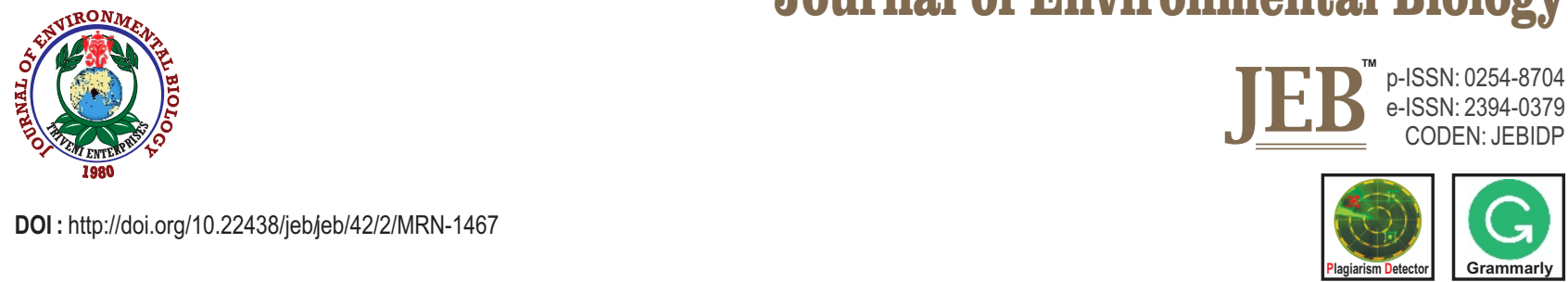

\title{
Species diversity of Ganoderma causing foot rot of arecanut in southern dry tracts of Karnataka
}

\author{
K.B. Palanna,,* S. Basavaraj', K.R. Shreenivasa ${ }^{2}$ and T. Narendrappa ${ }^{2}$ \\ 'ICAR-AICRP on Small Millets, PC Unit, University of Agricultural Sciences, Gandhi Krishi Vigyana Kendra, Bengaluru-560 065, India \\ ${ }^{2}$ Department of Plant Pathology, University of Agricultural Sciences, Gandhi Krishi Vigyana Kendra, Bengaluru-560 065, India \\ *Corresponding Author Email : kbpalanna@gmail.com
}

\section{Abstract}

Aim: The present study was undertaken to study the morphological and molecular diversity of Ganoderma spp. causing foot rot of arecanut in dry tracts of Southern Karnataka.

Methodology: A total of 20 samples isolated from diseased areca palms in three districts of Karnataka were identified based on morphological and molecular characteristics. Qualitative data of cultural characteristics were transformed into code and a binary matrix was generated. Total genomic DNA was isolated and ITS region was amplified using universal primers ITS1 and ITS4. PCR amplicon was directly sequenced and phylogenetic analysis was carried out.

Results: The dendrogram generated from the cultural morphological characteristics showed clear variations among Ganoderma isolates causing foot rot. DNA amplification of Ganoderma isolates with fungal universal primers (ITS1 and ITS4) was observed at $650 \mathrm{bp}$ in all isolates tested. Taxonomic correlation of isolates upon NCBI web proved that the isolates were genetically related to Ganoderma spp. with 89-99.49 per cent identity and confirmed the taxonomic identity of isolates used in this study.

Interpretation: Phylogenetic analysis of arecanut isolates of southern Karnataka are distinct as evidenced by forming separate cluster. Based on gene homology, G. ryvardenni and G. casuarinicola are new species reported as causal agent of foot rot in arecanut from Karnataka. The ITS gene sequences of four isolates viz., $A G_{3}\left(M N\right.$ 784436), $A_{4}$ (MN 784437), $\quad A G_{11}\left(M N\right.$ 784438), and $A G_{20}(M N$ 78449) were deposited in NCBI gene bank.

Key words: Arecanut, Foot rot, Ganoderma, Phylogeny, Species diversity

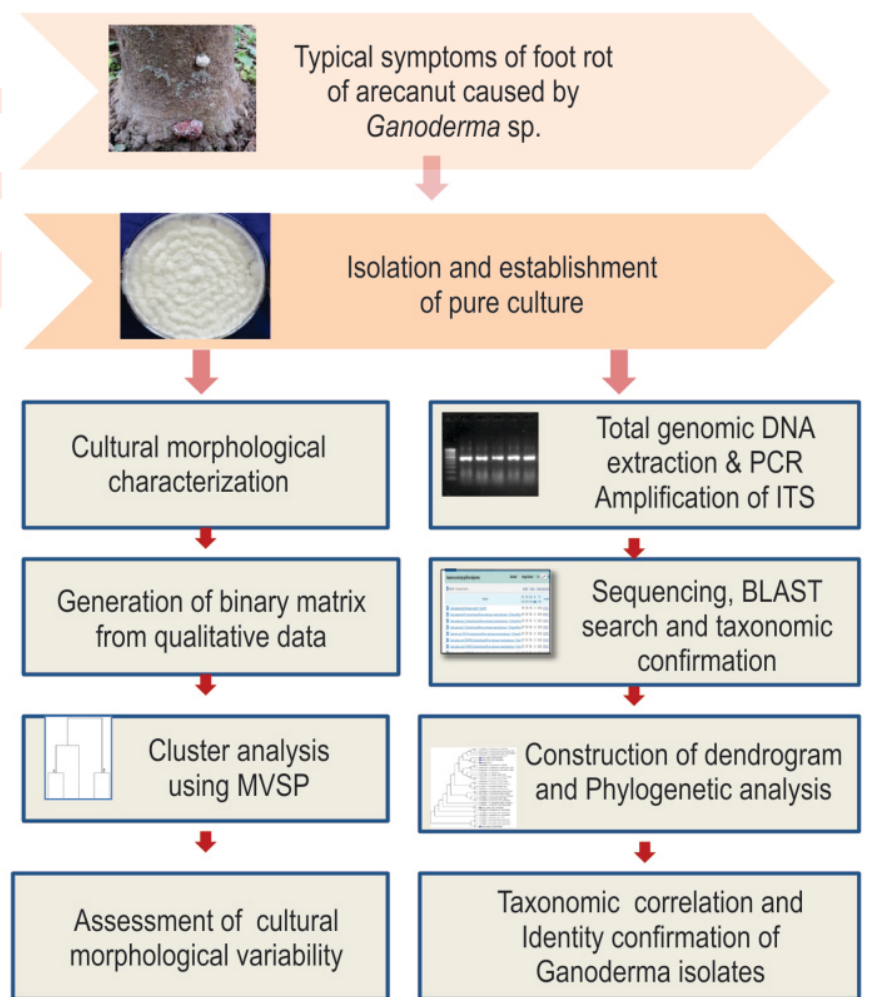

How to cite : Palanna, K.B., S. Basavaraj, K.R. Shreenivasa and T. Narendrappa: Species diversity of Ganoderma causing foot rot of arecanut in southern dry tracts of Karnataka. J. Environ. Biol., 42, 192-202 (2021). 


\section{Introduction}

Arecanut (Areca catechu L.) is a tropical plant found all over South-EastAsia. The fruit (nut) of this tree is popularly known as betel nut or supari in India. This is an important commercial crop of the region and also forms a part of ritual offerings in Hindu religion. Areca is taken up from the Malayan language, which means 'cluster of nuts'. The current production of arecanut in the world is about 127 thousand tonnes from an area of 925 thousand ha. India ranks first in both area (55\%) and production (45\%) of arecanut. Arecanut is the major plantation crop of coastal and southern districts of the country under assured irrigation facility. Production of arecanut in India is mainly concentrated in six states, namely Karnataka, Kerala, Assam, Meghalaya, Tamil Nadu and West Bengal. The Karnataka and Kerala are predominant states in the production of arecanut. Karnataka stands in first place in terms both area (48\%) and production (56 $\%$ ) and Kerala stands in second place in terms of area (21\%) and production (18\%). In Karnataka, six districts produce arecanut crop, out of which, Shivamogga stands first both in area and production (Bangarappa and Shiralashetti, 2018).

Areacanut palms are normally affected by various biotic and abiotic stresses resulting in drastic reduction in yield. Among various biotic stress that affect arecanut production in India, Foot rot (Anabe roga in Kannada) caused by Ganoderma is a major constraint in arecanut production, especially in dry tracts of Southern Karnataka. Ganoderma wilt in coconut and foot rot in arecanut caused by Ganoderma spp. is one of the most devastating disease affecting production and productivity of palms (Palanna, et al., 2020). The disease is reported from various places all over the tropical world. Foot rot was reported by Coleman from Karnataka in 1911 (Coleman, 1911). This disease is also reported from Kerala, Assam, West Bengal (Sharples, 1928) and Nicobar Islands (Sangal et al., 1961) and also from parts of Tamil Nadu. Naik et al. (2000) and Palanna et al. (2009, 2016) reported Ganoderma wilt incidence from Southern Karnataka on coconut.

The taxonomy of basidiomycetes is traditionally based on the morphological features of basidiocarps. Identification based on the basidiocarp features, however, is prone to problems such as absence of basidiocarps during certain time of the year, their morphological plasticity and presence of cryptic species (Moncalvo and Ryvarden, 1997; Gottlieb and Wright, 1999). However, studies have shown that Ganoderma species are genetically heterogeneous since wide range of genetic variation are reported and caused by out crossing over generations and different geographical origins (Miller et al., 1999; Pilotti et al., 2003). This leads to variation in their morphological characteristics even within same species (Hong et al., 2001). For these reasons, contemporary taxonomists employ morphological studies, mating tests, analyses of biochemical and DNA sequence information or combination of these methods for the identification of the pathogen. Recently, molecular approach has been adopted to identify Ganoderma species through multiplex polymerase chain reaction (PCR) which is a more rapid and precise approach (Idris et al., 2010; Wong et al., 2012). Disease management is an important aspect to sustain the palm industry. Lack of knowledge of the pathogen may lead to inaccurate disease control strategies. Hence, the present study was undertaken to investigate the diversity of Ganoderma species isolated from foot rot infected arecanut palms in terms of their morphological and molecular characteristics.

\section{Materials and Methods}

Collection of diseased root samples/stem bit and sporocarps of arecanut: Different parts of arecanut palms such as diseased root bits/stem bits affected by Ganoderma foot rot showing typical symptoms and sporocarps were collected from infected palms from different places of Southern Karnataka (Table 1). Total twenty samples were collected, labeled and packed in polythene bags and brought to the laboratory for the isolation of causal organism.

Isolation and designation of causal organism isolates: Infected roots/ stem bits collected from infected arecanut palms were washed thoroughly with sterile water, cut into small bits/ pieces and surface sterilized in $0.1 \%$ mercuric chloride for 30 sec and washed three times serially in sterile distilled water to remove the traces of mercuric chloride. After surface sterilization, diseased specimens were kept in sterilized bags along with wet cotton under room temperature for about 8 to 10 days. After 8 to 10 days of incubation period, slight mycelial growth observed was transferred onto Potato Dextrose Agar medium. The inoculated plates were incubated at room temperature $\left(28^{\circ} \mathrm{C} \pm 2{ }^{\circ} \mathrm{C}\right)$ for $3-5$ days to facilitate fungal growth. Later, a small portion of fungal growth was transferred to PDA slants. Pure culture of fungus was obtained by following hyphal tip culture technique under aseptic conditions. These isolates of Ganoderma isolated from arecanut were designated

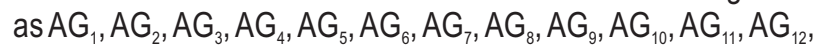
$A G_{13}, A G_{14}, A G_{15}, A G_{18}, A G_{19}, A G_{20}, A_{21}$ and $A G_{22}$, respectively.

Maintenance of pure cultures: The isolated fungus was subcultured on PDA slants and allowed to grow at $28^{\circ} \mathrm{C} \pm 2{ }^{\circ} \mathrm{C}$ temperature for $8-10$ days. The cultures so obtained were stored in refrigerator at $4^{\circ} \mathrm{C}$ for further studies and they were cultured periodically once a month.

Study on variability of Ganoderma isolate isolated from arecanut: Twenty Ganoderma isolates of arecanut isolated during course of investigation were used for variability study.

\section{Cultural morphological variability of Ganoderma isolates}

Growth on potato dextrose agar: Twenty Ganoderma isolates $\left[\mathrm{AG}_{1}, \mathrm{AG}_{2}, \mathrm{AG}_{3}, \mathrm{AG}_{4}, \mathrm{AG}_{5}, \mathrm{AG}_{6}, \mathrm{AG}_{7}, \mathrm{AG}_{8}, \mathrm{AG}_{9}, \mathrm{AG}_{10}, \mathrm{AG}_{11}, \mathrm{AG}_{12}\right.$, $A G_{13}, A G_{14}, A G_{15}, A G_{18}, A G_{19}, A G_{20}, A G_{21}$ and $A G_{22}$ ] of arecanut collected from different geographic locations were cultured on PDA. Morphological characters like colony diameter/ growth, biomass production, colony colour, colony margin, mycelial density, appearance of zones, reverse pigmentation etc. were 
studied. Mycelial plug $(6 \mathrm{~mm})$ from 7 day old active culture was transferred onto the centre of a standard $9 \mathrm{~cm}$ PDA plate and incubated for 7 days at an ambient temperature (Idris et al., 2000). The test for all isolates was run simultaneously to avoid bias due to external factors. The experiment was conducted in three replications. The diameter was measured daily and the number of days required for maximum growth of mycelium was also recorded. The texture of colony, appearance of zone, reverse pigmentation colour, type of colony margin and mycelial density were recorded after $7^{\text {th }}$ day of incubation.

Growth in liquid media: Flasks containing $100 \mathrm{ml}$ of sterilized potato dextrose broth were inoculated with mycelial discs of Ganoderma isolates of arecanut. Three replications were maintained for each treatment. The inoculated flasks were incubated at room temperature $\left(28 \pm 2{ }^{\circ} \mathrm{C}\right)$ for 10 days, and then mycelial mat was harvested on a previously weighed Whatman No. 4 filter paper and dried at $60^{\circ} \mathrm{C}$ in a hot air oven till constant weight was obtained. Dry mycelial weight was recorded and

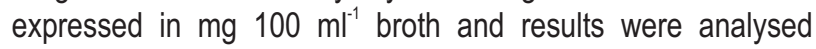
statistically. Qualitative data of cultural characteristics on solid media and biomass were transformed into code and a binary matrix was generated (Table 2). Binary data was subjected to cluster analysis using multivariate statistical package (MVSP version 3.13). Similarity matrices were calculated using simple matching coefficient and a dendrogram was generated using unweighted pair group method of arithmetic averages (UPGMA) (Pilotti et al., 2004).

Molecular characterization of Ganoderma: Isolates of Ganoderma species were identified through ITS (Internal Transcribed Spacer) region using universal primers ITS1 and ITS4 amplification.

Reagents and Chemicals: All the chemicals were of analytical grade and were from Sigma and Merck. The following buffers and solutions were prepared : Extraction buffer $(100 \mathrm{mmM}$ Tris- $\mathrm{HCl}$ (pH 8); 20 mM EDTA (pH 8); 2 M Nacl; 3 \% CTAB (w/v); $1 \%$ PVP; $2 \% \beta$-mercaptoethanol (v/v); phenol: chloroform (24:1); potassium acetate $7.5 \mathrm{M}$; proteinase $\mathrm{K}, 0.05 \mathrm{mg} \mathrm{ml}^{-1}$; wash solution [15 mM ammonium acetate in $75 \%$ (v/v)ethanol ]; TE buffer [10 mM Tris-HCl (pH 8), 1 mMEDTA(pH8)].

Fungal genomic DNA extraction: Fungal mycelia (100 mg) was ground in to fine powder using liquid nitrogen. Pre-warmed extraction buffer $(1 \mathrm{ml})$ was added to the samples and grounded once more in buffer. All the samples were transferred to Eppendorf tubes and $5 \mu$ proteinase $\mathrm{K}$ was added. The tube was incubated in $37^{\circ} \mathrm{C}$ for $30 \mathrm{~min}$ and then at $65^{\circ} \mathrm{C}$ for another $30 \mathrm{~min}$ with frequent swirling. Samples were centrifuged at 10,000 x g for $10 \mathrm{~min}$ at room temperature and the supernatant was transferred to fresh Eppendorf tube. To the supernatant, $100 \mu \mathrm{l}$ of $7.5 \mathrm{M}$ potassium acetate was added and incubated at $4{ }^{\circ} \mathrm{C}$ for $30 \mathrm{~min}$. The samples were centrifuged at $13,000 \times \mathrm{g}$ for $10 \mathrm{~min}$ at RT; the supernatant was transferred to fresh tube, an equal volume of chloroform: isoamyl alcohol was added and mixed by gentle inversion 30-40 times. The samples were centrifuged at 10,000 $\mathrm{x}$ $\mathrm{g}$ for $10 \mathrm{~min}$ at room temperature. The supernatant was transferred to a fresh tube and precipitated with $2 / 3$ volume of isopropanol. The precipitated nucleic acids were collected and washed twice with the wash solution. The nucleic acid pellet so obtained was air dried untill the traces of ethanol was removed and dissolved in an appropriate amount of TE buffer $(50-70 \mu \mathrm{l})$. Nucleic acid dissolved in TE buffer were treated with ribonuclease, incubated at $37^{\circ} \mathrm{C}$ for 30 min and stored at $-20^{\circ} \mathrm{C}$ until further use.

Qualitative and quantitative analysis of DNA: The quality and quantity of DNA was analyzed by running $2 \mu$ of each sample mixed with $2 \mu$ of $10 x$ loading dye in one per cent agarose gel. DNA from all the isolates produced clear sharp bands in one per cent agarose gel indicating good quality of DNA. DNA was also quantified by spectrophotometer (Nanodrop ND 1000).

PCR amplification of Internal Transcribed Spacer (ITS) region: Ribosomal DNA (rDNA) unit contains genetic and nongenetic or spacer region. Each repeat unit consists of a copy of 18S, 5.8S and 28S like rDNA and its spacer like Internal Transcribed Spacers (ITS) and Inter-Genic Spacers (IGS). rDNA is used to analyze evolutionary events because it is highly conserved whereas ITS rDNA is more variable. Hence, it is used for investigating the species level relationships. The primers for amplification were custom synthesized at Bangalore Genie Pvt. Ltd., Bangalore and supplied as lyophilized products of desalted oligos. Primer sequences for amplification of ITS region used were as follows:

PCR was carried out in poly propylene tubes using universal primers ITS 1 (5' -AACGTTACCAAACTGTTA-3') and ITS 4 (5' -AAGTTCAGCGGGTATTCCT-3') and G. lucidum specific primers GSF (5' -CCCTAAACCTCTCAAAGTCA-3') and GSR (5' - TATCGTACAGGTTCTCGTG -3). PCR amplification was performed in $25 \mu$ l reaction mixture containing $10 \times$ reaction buffer supplied by the manufacturer, $100 \mathrm{ng}$ of fungal DNA, each dNTP at a concentration of $0.5 \mathrm{mM}$, 20 pico moles of each primer and $1 \mathrm{U}$ of Taq DNA polymerase (NEB, USA). Thermo cycling conditions were $94^{\circ} \mathrm{C}$ for $5 \mathrm{~min}$, followed by 30 cycles of $94^{\circ} \mathrm{C}$ for $30 \mathrm{sec}, 56^{\circ} \mathrm{C}$ for $1 \mathrm{~min}$ and $72^{\circ} \mathrm{C}$ for $1 \mathrm{~min}$ and a final elongation step of $72^{\circ} \mathrm{C}$ for $5 \mathrm{~min}$.

Separation of amplified products by agarose gel electrophoresis: Agarose gel electrophoresis was performed to resolve the amplified product using $1.4 \%$ agarose in $1 \mathrm{XTBE}$ (Tris Borate EDTA) buffer, $0.5 \mathrm{mg} \mathrm{ml}^{-1}$ of ethidium bromide and loading buffer ( $0.25 \%$ bromophenol blue in $40 \%$ sucrose). One microliter of loading dye was added to $5 \mu$ l of PCR product and loaded into agarose gel. Electrophoresis was carried at $65 \mathrm{~V}$ for $1.5 \mathrm{hr}$. The gel was observed under UV light and documented using gel documentation unit.

Sequencing of ITS region: The ITS region was sequenced from the isolates of Ganoderma species to confirm the organism and to the variability present in them. Homology search was done using 
BLAST algorithm (Basic Local Alignment Search Tool). www. ncbi. nlm. nih, gov/BLAST/available at the http://www.ncbi. nIm.nih.gov and phylogenetic trees constructed using the neighbor joining method (gopher:// megasum. bch, umntreal. ca: 70/11/GDE).

\section{Results and Discussion}

The perusal of data revealed cultural morphological variations between isolates of Ganoderma isolated from infected palms of arecanut in southern dry tracts of Karnataka. The colony diameters on $5^{\text {th }}, 7^{\text {th }}$ and $9^{\text {th }}$ day after inoculation varied significantly among arecanut isolates, where radial growth ranged from 2.08 to $7.83 \mathrm{~cm}$ on $5^{\text {th }}$ day after inoculation. Similarly on $7^{\text {th }}$ and $9^{\text {th }}$ day also it varied significantly. Many variations were observed with respect to colony/ mycelial characteristics in different isolates of arecanut (Table 3, Fig. 1 and 2). The number of days taken to cover full plate ranged from 7 to 18 days and few isolates covered entire plate in 7 days, as observed in $A G_{1}, A G_{7}$, $\mathrm{AG}_{8}, \mathrm{AG}_{9}, \mathrm{AG}_{21}$ and $\mathrm{AG}_{22}$. However, most isolates took more than 10 days to cover the entire plate. The biomass production also varied significantly between different isolates of Ganoderma. Many of variation were observed with respect to colony/ mycelial characteristics of different isolates of Ganoderma (Table 3, Fig. 1 and 2). Dendrogram generated from cultural morphological characteristics of Ganoderma isolates showed clear variations among them. The isolate $A G_{15}$ and $A G_{2}$ were distinct. Complete similarity $(100 \%)$ was found in several isolates of Ganoderma regardless of their geographical origin (Fig. 2). The present study is in agreement with the findings of Rakib et al. (2014) who had studied genetic morphological variability in forty six isolates of Ganoderma causing basal stem rot and upper stem rot in oil palm and reported significant variations within and between Ganoderma species in terms of their cultural morphology and basidiospore characteristics, and also reported that cluster analysis of cultural morphology and scattered plot of basidiospore features indicated in distinct relationship within and between species, disease types or geographical origins of Ganoderma species. Wide range of variation in morphological characteristic can be related to heterogeneity of Ganoderma species.

Cultural characteristic that distinguished $G$. zonatum from $G$. boninense and $G$. miniatocinctum was wavy characteristic of the colony in $G$. zonatum. However, this characteristic also varied and was not present in all $G$. zonatum isolates. Furthermore, the cultural appearances of fungi were also highly dependent on several factors such as type of media, $\mathrm{pH}$ and temperature (Adaskaveg and Gilbertson, 1989). Although similar (100\% similarity) cultural morphological features were observed between $\mathrm{G}_{3}$ and $\mathrm{G}_{4}, \mathrm{G}_{15}$ and $\mathrm{G}_{33}, \mathrm{G}_{19}$ and $\mathrm{G}_{27}$, and $\mathrm{G}_{30}$ and $\mathrm{G}_{31}$ based on the dendrogram generated, they were still genetically different based on the somatic incompatibility between the isolates. This showed that different genotype in Ganoderma species may express similar morphological features (phenotype). The dendrogram also showed similar species of Ganoderma may be separated by up to $40 \%$ dissimilarity, while

Table 1: Identity and designation of Ganoderma isolates of arecanut and their source of collection

\begin{tabular}{lll}
\hline Source of isolation & Collection site & $\begin{array}{l}\mathrm{Identity} \mathrm{and} \mathrm{designation} \mathrm{of} \\
\mathrm{Ganoderma} \mathrm{isolates}\end{array}$ \\
\hline Root sample & Mallenahally, Channarayapattana Tq. Hassan Dist. & $\mathrm{Ag}_{1}$ \\
Root sample & Jodigatte, Channarayapattana Tq. Hassan Dist. & $\mathrm{Ag}_{2}$ \\
Sporocarp & Shettikere, C.N.Halli Tq. Tumkur Dist. & $\mathrm{AG}_{3}$ \\
Sporocarp & Thimmanahalli, C.N.Halli Tq. Tumkur Dist. & $\mathrm{AG}_{4}$ \\
Root sample & Hosuru, BeluruTq. Hassan Dist. & $\mathrm{Ag}_{5}$ \\
Sporocarp & Bidarahally, HassanTq. Hassan Dist. & $\mathrm{Ag}_{6}$ \\
Root sample & Adivala Hiriyur Tq. Chitradurga Dist. & $\mathrm{Ag}_{7}$ \\
Root sample & Hosahally, TipturTq. Tumkur Dist. & $\mathrm{Ag}_{8}$ \\
Sporocarp & Kodipalya, Tumkur Tq. Tumkur Dist. & $\mathrm{Ag}_{9}$ \\
Root sample & Vadavalughatta, TipturTq. Tumkur Dist. & $\mathrm{Ag}_{10}$ \\
Sporocarp & Thyagaturu, Gubbi Tq. Tumkur Dist. & $\mathrm{Ag}_{11}$ \\
Sporocarp & Nagalapura, Gubbi Tq. Tumkur Dist. & $\mathrm{Ag}_{12}$ \\
Root sample & Kalkodi, Gubbi Tq. Tumkur Dist. & $\mathrm{Ag}_{13}$ \\
Root sample & Ammanagatta, Gubbi Tq. Tumkur Dist. & $\mathrm{Ag}_{14}$ \\
Root sample & Doddenahalli, Turvekere Tq. Tumkur Dist. & $\mathrm{Ag}_{15}$ \\
Root sample & Doddanaramangala Tumkur Tq Tumkur dist & $\mathrm{Ag}_{18}$ \\
Sporocarp & Chiknaramangla Tumkur Tq. Chitradurga Dist. & $\mathrm{Ag}_{19}$ \\
Root sample & Doddakittadahalli, HosdurgaTq. Chitradurga Dist. & $\mathrm{Ag}_{20}$ \\
Root sample & Krishnagiri, Hiriyur Tq. Chitradurga Dist. & $\mathrm{Ag}_{21}$ \\
Root sample & Malsandra Tumkur Tq. Chitradurga Dist. & $\mathrm{Ag}_{22}$ \\
\hline
\end{tabular}

Note: AG-Arecanut Ganoderma 
Table 2: Cultural morphological characters and their corresponding codes used to describe Ganoderma isolates for assessment of cultural morphological characteristics

\begin{tabular}{lll}
\hline Characters & Description & Code \\
\hline Days for full plate & $<8$ & 1 \\
& $8-9$ & 2 \\
& $10-11$ & 3 \\
Biomass $\left(\mathrm{g} 100 \mathrm{ml}^{-1}\right)$ & $>11$ & 4 \\
& $<1$ & 5 \\
& $1-1.25$ & 6 \\
Colony colour & $>1.25$ & 7 \\
\multirow{3}{*}{ Mycelia texture } & White & 8 \\
& Creamy white & 9 \\
\multirow{3}{*}{ Concentric rings } & Smooth & 10 \\
Reverse pigmentation & Leathery & 11 \\
& Fluffy & 12 \\
& Present & 13 \\
& Absent & 14 \\
& No pigmentation (White) & 15 \\
& Pale yellow & 16 \\
& Yellowish & 17 \\
& Yellow & 18 \\
Mycelia density & Pinkish & 19 \\
& Thin & 20 \\
& Dense & 21 \\
Margin & Thin at center and dense at corner & 22 \\
& Dense at center & 23 \\
& Filamentous & 24 \\
& Even & 25 \\
& Undulate & 26 \\
& Erose & 27 \\
& Lobate & 28 \\
\hline
\end{tabular}

different species of Ganoderma may have up to $92 \%$ similarity. This indicates that Ganoderma species in an oil palm plantation can not be separated according to their species, disease type or geographical origins based on their cultural morphological features. Hence, cultural characteristics observed in this study may not be useful as an identification tool. More precise tool such molecular techniques/tools should be used to identify the Ganoderma species accurately (Rakib etal., 2014).

Genomic DNA of different isolates of Ganoderma was isolated by CTAB method, and the size was determined by resolving on one per cent agarose gel. The DNA obtained was about 600-650bp compared to the whole genomic DNA of Ganoderma spp. The concentration of DNA was determined using nanodrop equipment and the concentration was approximate by $75 \mu \mathrm{g} \mathrm{I}^{-1}$

Full length ITS rDNA region was amplified with ITS region with fungal universal primers (ITS1 and ITS4) and G. lucidum specific primers from total genomic DNA of all five isolates of Ganoderma. DNA amplicon was $600-650$ bp in length in universal primers (Fig.3) and DNA was not amplified with G. lucidum specific primers. The results revealed that $G$. lucidum species was absent in Ganoderma isolates tested. Further, the species identity was confirmed with DNA sequencing.

The ITS rDNA fragments of Ganoderma isolates were sequenced and DNA amplification from Ganoderma was observed at good specificity for the genus Ganoderma and approximately 600-650 bp product was exclusively amplified in all the isolates tested with fungal universal primers. DNA sequences of selected isolates of arecanut were compared using bioinformatics tool like NCBI (National Centre for Bioinformatics) BLAST programme. Based on the sequence comparison, identification of Ganoderma isolates was confirmed and all the ITS rDNA sequences of the isolates were confirmed as of Ganoderma sp. with $89-99.49 \%$ identity. The list of isolates, source of isolation and accession number are given in Table 4 and Phylogenetic tree of Ganoderma constructed with ITS region sequences is shown in Fig. $4 \mathrm{a}$ and $4 \mathrm{~b}$.

Abundance and uniform distribution of genetic markers in any pathogen is necessary for diversity analysis at various levels. Presently, DNA markers are a class by themselves. Almost unlimited in number, they are widely and evenly distributed in the genome. Unaffected by other genes and environment, genotype of any individual of a population with respect to DNA based markers can be determined unequivocally at any stage of the development non-destructively. In addition, it is possible to generate markers to suite specific applications without altering the genotype of the individuals. It is difficult to distinguish these species using traditional morphological and physiological differences. To understand existence of variation among the isolates of pathogens, PCR based technique, i.e., ITS (Internal Transcribed Sequence) was used in the present investigation. Variations in morphological characteristics of Ganoderma have led taxonomists to introduce biochemical and molecular methods to differentiate Ganoderma species (Muthelo, 2009).

DNA amplification from Ganoderma was observed at good specificity for the genus Ganoderma, and approximately 600-650 bp product was exclusively amplified in all the isolates tested with fungal universal primers. However, DNA amplification was not amplified with $G$. Iucidum specific primers in the isolates tested. Ribosomal genes and their ITS and IGS spacer regions have been widely used for the identification and differentiation of species (Fouly et al., 1997) as well as in taxonomic (Driver et al., 2000), phylogenetic (Rakotonirainy et al., 1994) and genetic diversity (Anderson et al., 2001; Uetake et al., 2002) studies with ITS sequences having been reported as useful for discriminating between different species of fungi (Neuveglise et al., 1994; Fouly et al., 1997; Jensen et al., 2001; Anderson et al., 2001; Thomsen and Jensen, 2002). ITS regions have been successfully used to generate specific primers capable of differentiating closely related fungal species.

Amplification of target DNA through PCR with taxonspecific primers is potentially more sensitive and accurate approach than conventional microscopic techniques. Nucleotide sequences from certain regions of DNA reflect phylogeny at 
Table 3: Cultural and morphological characteristics/variability of Ganoderma isolates of arecanut*

\begin{tabular}{|c|c|c|c|c|c|c|c|c|c|}
\hline \multirow[b]{2}{*}{ Isolates } & \multicolumn{3}{|c|}{ Radial growth (cm) } & \multirow{2}{*}{$\begin{array}{l}\text { Days } \\
\text { taken to } \\
\text { cover } \\
\text { plate }\end{array}$} & \multicolumn{5}{|c|}{ Colony/ Mycelial characters } \\
\hline & $5 \mathrm{DAl}$ & 7 DAl & $9 \mathrm{DAl}$ & & $\begin{array}{l}\text { Biomass } \\
\mathrm{g} / 100 \mathrm{ml}\end{array}$ & $\begin{array}{l}\text { Colour/reverse } \\
\text { pigmentation }\end{array}$ & $\begin{array}{l}\text { Texture/ } \\
\text { density }\end{array}$ & $\begin{array}{l}\text { Concentric } \\
\text { Rings }\end{array}$ & Margin \\
\hline$A G_{1}$ & 7.22 & 9.00 & 9.00 & 7 & 1.23 & White/white & Fluffy/dense & - & Even \\
\hline $\mathrm{AG}_{2}$ & 3.75 & 4.87 & 6.21 & 11 & 0.80 & White/white & Fluffy/dense & + & Lobate \\
\hline $\mathrm{AG}_{3}$ & 3.00 & 3.60 & 5.08 & 15 & 0.87 & White/pinkish & Leathery & - & Erose \\
\hline $\mathrm{AG}_{4}$ & 2.08 & 2.90 & 4.25 & 17 & 0.89 & White/yellowish & Leathery & - & Undulate \\
\hline $\mathrm{AG}_{5}$ & 2.84 & 3.98 & 6.00 & 12 & 1.00 & White/pinkish & Fluffy/dense & - & Undulate \\
\hline $\mathrm{AG}_{6}$ & 2.22 & 3.46 & 5.75 & 13 & 0.76 & White/white & Fluffy/dense & + & Even \\
\hline $\mathrm{AG}_{7}$ & 7.58 & 9.00 & 9.00 & 7 & 1.26 & White/yellowish & Fluffy/dense & - & Filamentous \\
\hline $\mathrm{AG}_{8}$ & 6.87 & 8.57 & 9.00 & 7 & 1.30 & White/yellowish & Fluffy/dense & - & Even \\
\hline $\mathrm{AG}_{9}$ & 7.31 & 9.00 & 9.00 & 7 & 1.36 & White/yellowish & Fluffy/dense & - & Even \\
\hline$A G_{10}$ & 4.18 & 6.08 & 7.87 & 11 & 0.84 & White/yellowish & Fluffy/dense & + & Filamentous \\
\hline$A G_{11}$ & 3.26 & 5.77 & 8.07 & 12 & 0.78 & Creamy/ yellowish & Fluffy/thin & + & Even \\
\hline$A G_{12}$ & 3.08 & 5.21 & 6.89 & 13 & 0.95 & White/pinkish & Fluffy/dense & - & Undulate \\
\hline $\mathrm{AG}_{13}$ & 2.95 & 4.13 & 5.50 & 14 & 0.88 & White/white & Fluffy/thin & - & Filamentous \\
\hline$A G_{14}$ & 6.97 & 8.00 & 9.00 & 8 & 1.05 & Creamy white/yellowish & Leathery/dense & - & Filamentous \\
\hline $\mathrm{AG}_{15}$ & 7.83 & 8.57 & 9.00 & 8 & 1.13 & White/ yellowish & Fluffy/dense & + & Filamentous \\
\hline $\mathrm{AG}_{18}$ & 2.08 & 2.65 & 4.75 & 18 & 0.56 & White/white & Fluffy/thin & - & Even \\
\hline$A G_{19}$ & 2.14 & 3.00 & 6.45 & 16 & 0.74 & Creamy White/white & Leathery/dense & + & Filamentous \\
\hline $\mathrm{AG}_{20}$ & 4.95 & 6.14 & 8.20 & 11 & 1.03 & White/ yellowish & Fluffy/dense & - & Filamentous \\
\hline $\mathrm{AG}_{21}$ & 7.67 & 9.00 & 9.00 & 7 & 1.22 & White/ yellowish & Leathery/dense & - & Filamentous \\
\hline $\mathrm{AG}_{22}$ & 5.26 & 9.00 & 9.00 & 7 & 1.20 & White/ yellowish & Fluffy/dense & + & Filamentous \\
\hline SEm \pm & 0.43 & 0.087 & 0.042 & & 0.273 & - & - & - & - \\
\hline$C D(p=0.01)$ & 1.81 & 0.822 & 0.622 & & 1.101 & - & - & - & - \\
\hline CV $(\%)$ & 13.93 & 4.77 & 2.98 & & 9.30 & - & - & - & - \\
\hline
\end{tabular}

Note: + Present; - Absent; DAI-Days After Inoculation *Mean of three replications

Table 4: Details of Ganoderma spp. nucleotide sequence data submitted to GenBank

\begin{tabular}{lllll}
\hline Crop & Source of isolation & Name of isolate & Gen Bank accession number & Site \\
\hline Arecanut & Sporocarps & $\mathrm{AG}_{3}$ & MN784436 & Shettikere, C.N.Halli Tq. Tumkur Dist. \\
Arecanut & Sporocarps & $\mathrm{AG}_{4}$ & MN784437 & Thimmanahalli, C.N.Halli Tq. Tumkur Dist. \\
Arecanut & Sporocarps & $\mathrm{AG}_{11}$ & MN784438 & Thyagaturu, Gubbi Tq. Tumkur Dist. \\
Arecanut & Root Samples & $\mathrm{AG}_{20}$ & MN78449 & Doddakittadahalli, HosdurgaTq. Chitradurga Dist \\
\hline
\end{tabular}

various taxonomic levels. Such regions evolve at an appropriate rate in order to supply enough consistent differences to separate the taxa into statistically supported monophyletic groups.

These regions must be present as a single copy in the genome or evolve as a single copy region in order to avoid comparison of different copies in different species (paralogous comparisons) if the region exists as multicopy. Also, the region should have similar function in all organisms (Mitchell et al., 1995). Ribosomal RNA (rRNA) genes, certain ribosomal elongation factors, and genes from nuclear and mitochondrial genomes have been useful for DNA sequence analysis in fungi (Tan and Niessen, 2003; Moreau et al., 2006). Consequently, nucleotide sequence information from relatively conserved genes/DNA segments such as ITS (Moncalvo et al., 1995a, b; Smith and Sivasithamparam, 2000), mitochondrial small subunit (mtSSU) (Hong and Jung, 2004), and nuclear large subunit (LSU) (Lee et al., 2006) rDNA have been widely used in the taxonomy and phylogeny of Ganoderma species because the variability of these regions, which is harboured mainly in the introns, provide sufficient resolution at various taxonomic levels. Phylogenetic analysis of ITS sequence data was used to resolve Australian Ganoderma isolates into five terminal clades, and showed that number of isolates had been misnamed (Smith and Sivasithamparam, 2000). Based on the phylogenetic analysis of ITS and 5.8S sequence, Latiffah et al. (2002) showed that Ganoderma isolates from infected oil palm and coconut stumps belonged to same group as classified by PCR-RFLP. Gottlieb et al. (2000) also used ITS- 


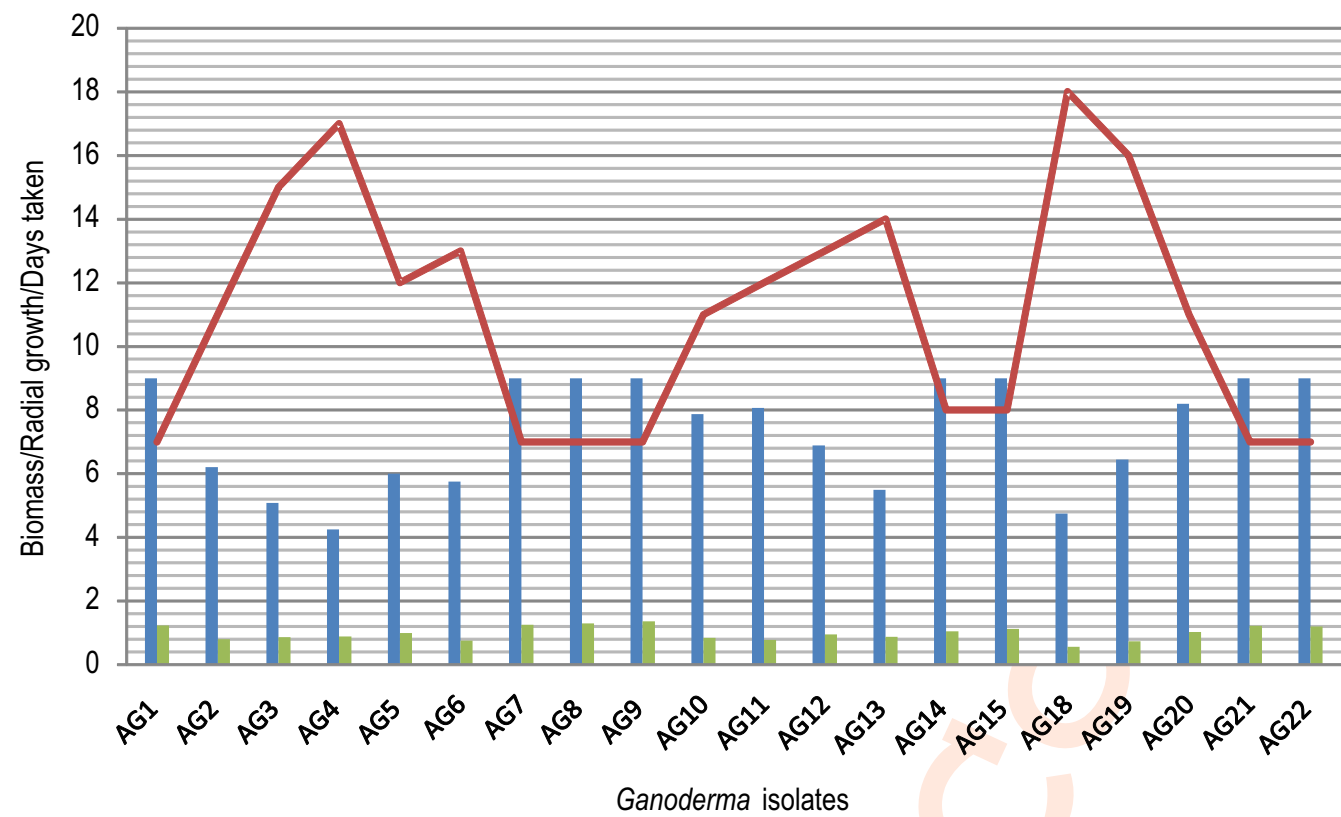

Radial growth $9 \mathrm{DAl}(\mathrm{cm})$

Bio mass $\left(\right.$ (g $\left.100 \mathrm{ml}^{-1}\right)$

Days taken to cover plate

Fig. 1: Cultural and morphological characteristics/variability of Ganoderma isolates of arecanut.

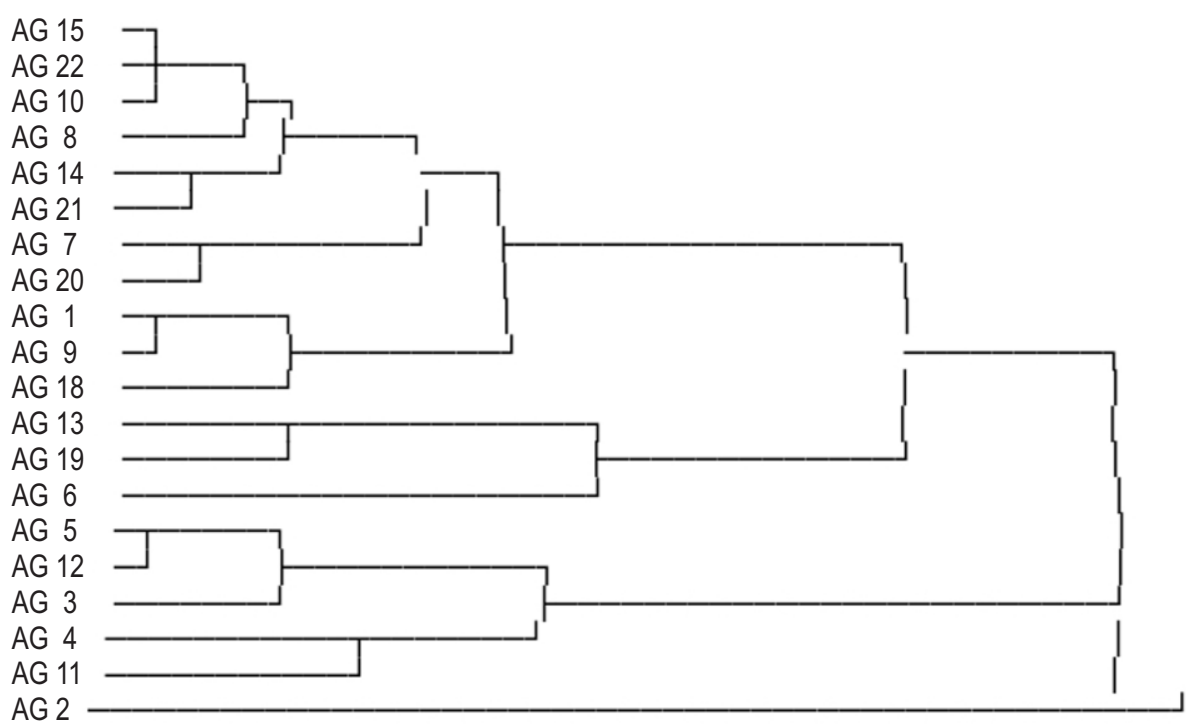

Fig. 2: Dendrogram showing relationships of Ganoderma isolates from arecanut based on similarity matrix of cultural/morphological characteristics.

based phylogenetic analysis together with PCR-RFLPs to elucidate the taxonomy of Ganoderma species in South America. They reported that molecular and morphological data agree at subgeneric level, however, it was difficult to determine relationship at species level. Gottlieb et al. (2000) adopted rDNAanalysis (ITS I and II of 5.8S rDNA) to identify South American isolates of Ganoderma and Elfvingia and found molecular and morphological agreement at subgeneric level, however, this relationship was difficult to visualize at species level. Singh et al. (2003) characterized 61 accessions using DNA finger printing technique and RAPD/ AFLP analysis revealed highly significant genetic variability among $G$. lucidum isolates collected from coconut gardens in Coimbatore. Earlier studies based on morphological identification asserted that North American G. Iucidum and European G. resinaceum belong to same biological species (Adaskavegand Gilbertson, 1986). 


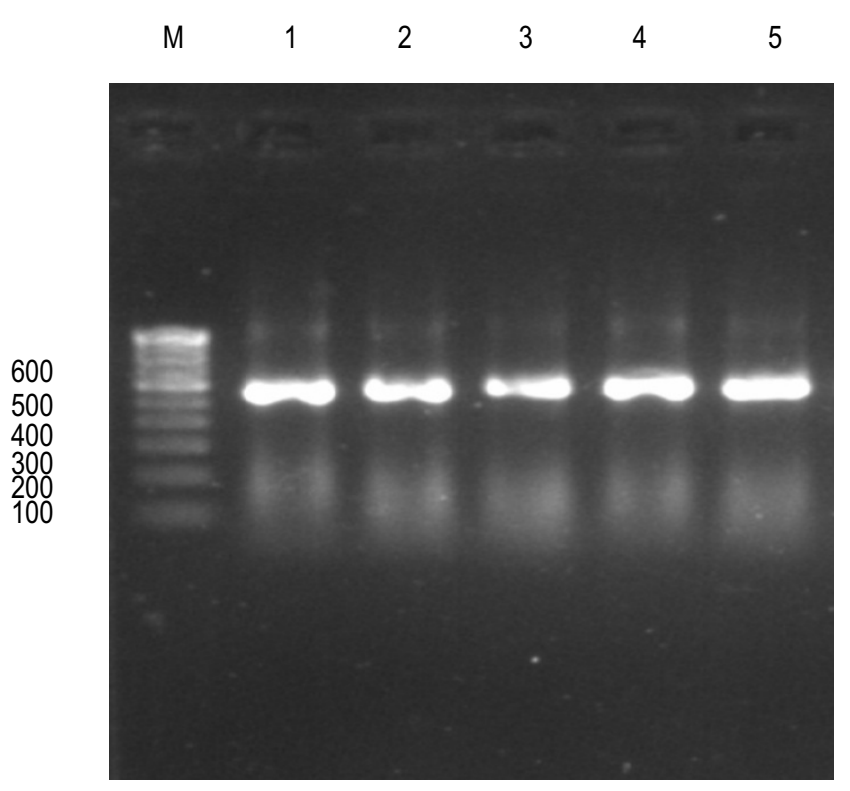

ITS primers

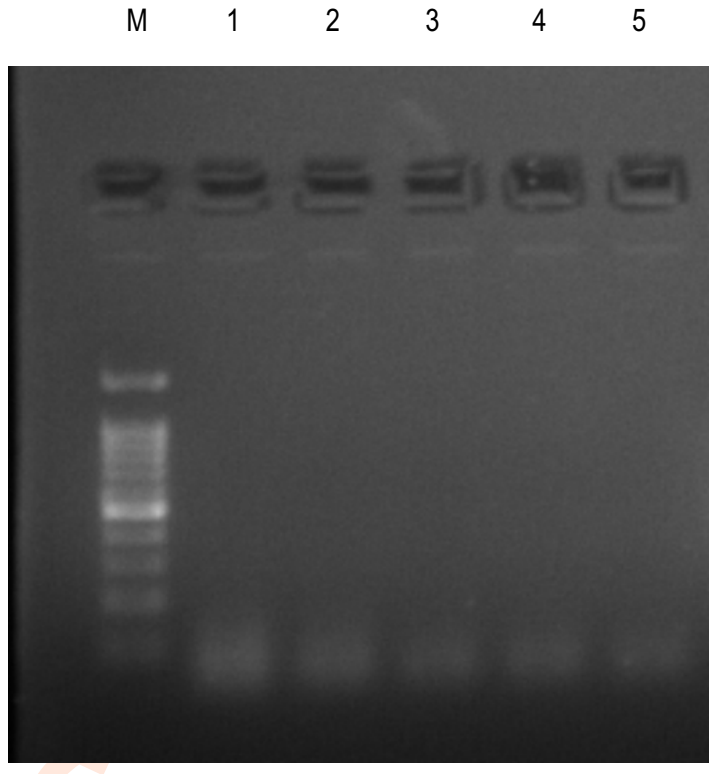

G. lucidum specific primers

Fig. 3: Gel picture showing PCR amplification of rDNA of Ganoderma isolates of arecanut with ITS1, ITS4 and G lucidum specific primers. Lane M= 100bp Ladder; Lane 1-5= Ganoderma isolates of arecanut.

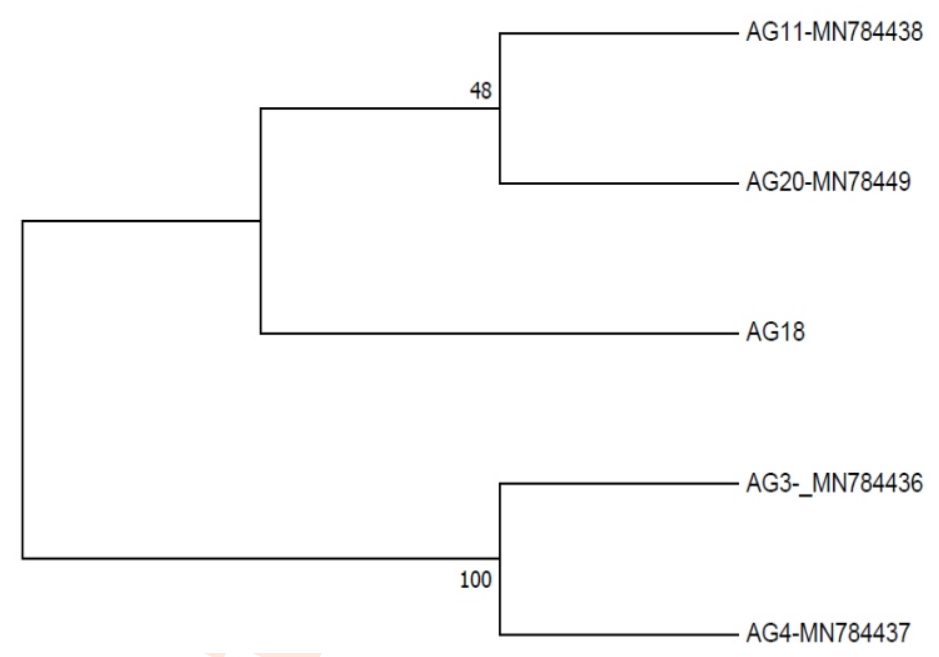

Fig. 4a: Phylogenetic relationships among Ganoderma isolates from arecanut inferred from the sequences of ITS region.

Based on phylogenetic relationships and nucleotide sequence variations of ITS (Moncalvo et al., 1995a, b) as well as $\mathrm{mtSSU}$ (Hong and Jung, 2004), these two species were found to be different. Gene phylogeny by Moncalvo et al. (1995b) indicated that isolates that were morphologically identified as $G$. lucidum did not cluster together, neither those identified as $G$. tsugae or $G$. resinaceum. In the phylogenetic analysis of Ganoderma species using mtSSU sequence data by Hong and
Jung (2004), Ganoderma species were divided into six monophyletic groups (G. colossus group, G. applanatum group, $G$. tsugae group, Asian G. Iucidum group, G. meredithiae group and $G$. resinaceum group) that included different species identified on the basis of morphological characters. Species identified as G. lucidum were scattered over three groups, the Asian $G$. lucidum group, the $G$. resinaceum group and the $G$. tsugae group. Also, isolates that were identified as G. oregonense 


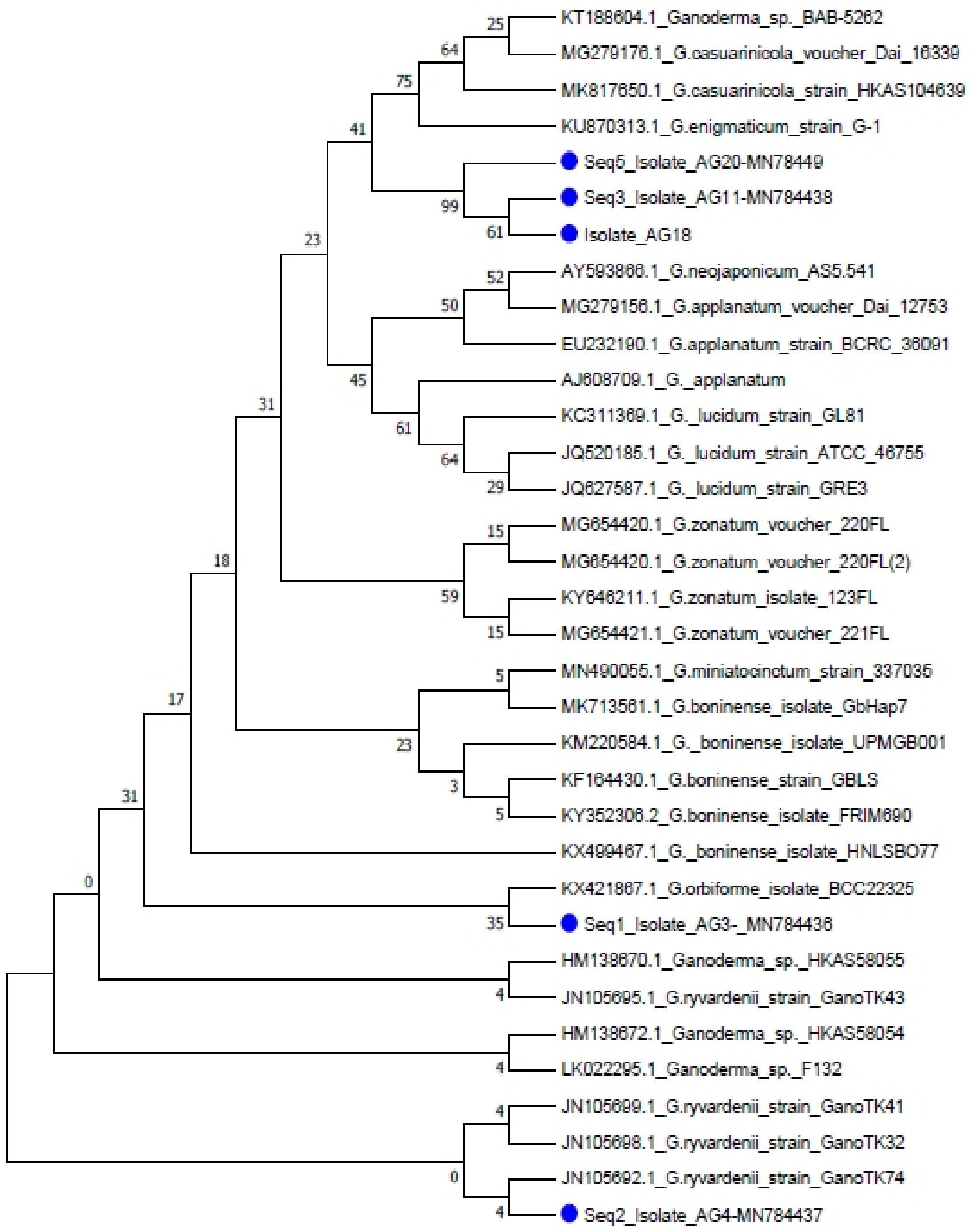

Fig. 4b: Phylogenetic relationships of Ganoderma isolates from arecanut inferred from the sequences of ITS region with known species of Ganoderma. 
and G. oerstedii did not group together. These two studies indicate that some isolates were misidentified based on morphological characters since isolates that were identified as one did not form a monophyletic group. From the previous discussions, it is apparent that DNA sequence analysis of ribosomal DNA region has provided an alternative approach to illuminate the taxonomy of Ganoderma. These techniques have played an important role in the taxonomy of Ganoderma, and have proved to be more reliable than other techniques used for same purpose. Misidentification and species synonyms based on morphological identification have been reduced using molecular techniques (Muthelo, 2009).

Taxonomic correlation of isolates upon NCBI web proved that the isolate were genetically related to Ganoderma spp. with 94-100\% identity. Phylogenetic analysis with other known species of Ganoderma from Gene Bank, $\mathrm{AG}_{2}$ and $\mathrm{AG}_{3}$ emphasize close relationship with $G$. ryvardenii and $G$. orbiforme isolated from Cameroon and Thailand. Isolates $A G_{11}, A G_{18}$ and $A g_{20}$ were found distinct by forming separate cluster and the results clearly indicated species diversity of Ganoderma in Southern Karnataka. Based on gene homology, G. ryvardenii and G. orbiforme are new species causing foot rot of arecanut in dry tracts Southern Karnataka. In this study, a combination of cultural/ morphological characteristics and molecular techniques allowed identification of groups within Ganoderma isolates of arecanut, and the results indicated existence of Ganoderma species diversity causing foot rot in dry tracts of Southern Karnataka.

\section{Acknowledgments}

The authors acknowledge AICRP on palms, Agriculture Research Station, Arsikere and the Department of Horticulture, Government of Karnataka for providing base line information on coconut cultivation and the Department of Plant Pathology, University of Agricultural Sciences, GKVK, Bengaluru for providing facilities to carry out this work.

\section{Add-on Information}

Authors' contribution: K.B. Palanna: Conceptualization, Data curation, Investigation, Methodology, Resources, Software, Supervision, Validation, Writing-Original draft, Writing-review and editing; S. Basavaraj, K.R. Shreenivasa, T. Narendrappa: Invistigation, Data curation, Methodology, Resources, Supervision, Writing-review and editing.

Research content: The research content is original and has not been published elsewhere

\section{Ethical approval: NotApplicable}

Conflict of interest: The authors declare that there is no conflict of interest.

Data from other sources: NotApplicable
Consent to publish: All authors agree to publish the paper in Journal of Environmental Biology.

\section{References}

Adaskaveg, J.E. and R.L. Gilbertson: Cultural studies of four North American species in the Ganoderma lucidum complex with comparisons to G. lucidum and G. tsugae. Mycol. Res., 92, 182191 (1989).

Adaskaveg, J.E. and R.L. Gilbertson: Cultural studies and genetics of sexuality of Ganoderma lucidum and $G$. tsugae in relation to the taxonomy of G. Iucidum complex. Mycologia, 78, 694-705 (1986).

Anderson, I.C., S.M. Chambers and W.G.J Cairney: ITS-RFLP and ITS sequence diversity in Pisolithus from central and eastern Australian sclerophyll forests. Mycol Res.,11, 1304-1312 (2001).

Bangarappa, B. and A.S. Shiralashetti: Growth in area of arecanut culativation and production: An overview. ZENITH Int. J. Multidiscip. Res., 8, 435-440 (2018).

Coleman, L.C.: 'Anabe roga' of supari. Annual Report for 1909-1910. Agric. Chemist Mysore, Dept. Agric. Bangalore, p. 32 (1911).

Driver, F., R.J. Milner and J.W.H. Trueman: A taxonomic revision of Metarhizium based on a phylogenetic analysis of rDNA sequence data. Mycol. Res., 104,134-150 (2000).

Fouly, H., H.T. Wilkinson and W. Chen: Restriction analysis of internal transcribed spacers and the small subunit gene of ribosomal DNA among four Gaeumannomyces species. Mycologia, 89, 590-597 (1997).

Gottlieb, A.M. and J.E. Wright: Taxonomy of Ganoderma from southern South America: subgenus Ganoderma. Mycolo. Res., 103, 661 673(1999)

Gottlieb, A.M., E. Ferrer and J.E. Wright: rDNA analyses as an aid to the taxonomy of species of Ganoderma. Mycolo. Res., 104, 1033$1045(2000)$.

Hong, K.K., S.S. Geon and G.K. Hong: Comparison of characteristics of Ganoderma lucidum according to geographical origins: Consideration of morphological characteristics. Micobiology, 29, 80-84 (2001)

Hong, S.G. and H.S. Jung: Phylogenetic analysis of Ganoderma based on nearly complete mitochondrial small subunit ribosomal DNA sequences. Mycologia, 96, 742-755 (2004).

Idris, A.S., D. Ariffin, T.R. Swinburne and T.A. Watt: The identity of Ganoderma species responsible for basal stem rot (BSR) disease of oil palm in Malaysia - Morphological characteristics. Malaysian Palm Oil Board Inform. Series, 102, MPOB TT No. 77a (2000).

Idris, A.S., S. Rajinder, A.Z. Madihah and M.B. Wahid: Multiplex PCRDNA kit for early detection and identification of Ganoderma species in oil palm. Malaysian Palm Oil Board Inform. Series, 531, MPOBTS No.73. (2010).

Jensen, A.B., L.Thomsen and J. Eilenberg: Intra specific variation and host specificity of Entomophtora muscae sensu stricto isolates revealed by random amplified polimorphic DNA, universal primed PCR, PCR-restriction fragment lenght polymorphism, and conidial morphology. J. Invert. Path., 78, 251-259 (2001).

Latiffah, Z., K. Harikrishna, S.G. Tan, S.H. Tan, F. Abdullah and Y.W. Ho: Restriction analysis and sequencing of the ITS regions and $5.8 \mathrm{~S}$ gene of rDNA of Ganoderma isolates from infected oil palm and coconut stumps in Malaysia. Associ. App. Biol., 141, 133-142 (2002).

Lee, J.S., M.K. Lim, K.Y. Cho, S.Y. Chang and D.H. Nam: Identification of medicinal mushroom species based on nuclear large subunit rDNA sequences. J. Microbiol., 44, 29-34 (2006).

Muthelo, VG: Molecular characterization of Ganoderma species. Magister Scientiae, University of Pretoria, Pretoria, South Africa (2009). 
Miller, R.N.G., M. Holderness, P.D. Bridge, G.F. Chung and M.H. Zakaria: Genetic diversity of Ganoderma in oil palm plantings. Plant Pathol., 48, 595-603 (1999).

Mitchell, J.I., P.J. Roberts and S.T. Moss: Sequence or structure?: A short review on the application of nucleic acid sequence information to fungal taxonomy. Mycologist, 9, 67-75 (1995).

Moncalvo, J.M. and L. Ryvarden: A nomenclature study of the Ganoderma taceae Donk. Sinop. Fung., 11, 1-14 (1997).

Moncalvo, J.M., H.H. Wang and R.S. Hseu: Phylogenetic relationships in Ganoderma inferred from the internal transcribed spacers and 25s ribosomal DNA sequences. Mycologia, 87, 223-238 (1995a).

Moncalvo, J.M., H.H. Wang and R.S. Hseu: Gene phylogeny of Ganoderma lucidum complex based on ribosomal DNA sequences. comparison with taxonomic characters. Mycol. Res., 99, 1489-1499 (1995b).

Moreau, P.A., U. Peintner and M. Gardes: Phylogeny of the ectomycorrhizal mushroom genus Alnicola (Basidomycota, Cortinariaceae) based on rDNA sequences with special emphasis on host specificity and morphological characters. Mol. Phylogen. Evol., 38, 794-807 (2006).

Naik, R.G., V. Palanimuthu, M. Hanumanthappa and K.M. Indiresh: Prevalence and intensity of basal stem rot disease of coconut in Arsikere taluk of Karnataka. Indian Coco. J., 31, 8-10 (2000).

Neuveglise, C., Y. Brygoo, B. Vercambre and G. Riba: Comparative analysis of molecular and biological characteristics of strains of Beauveria brongniartii isolated from insects. Mycol. Res., 98, 322328 (1994).

Palanna, K. B., K. R. Shreenivasa , S. Basavaraj and T. Narendrappa: Review of genus Ganoderma causing basal stem rot (Coconut) and foot rot (Arecanut) with respect etiology and management. Int. J. Curr. Microbiol. App.Sci., 9, 1434-1455 (2020).

Palanna, K.B., B. Boraiah, B. Shivanna, S. Bommalinga and M.S. Nagaraj: Incidence of Ganoderma wilt diseases of coconut with respect to agronomic practices in dry tracts of southern Karnataka. Enviro. Ecol, 34, 24-128 (2016).

Palanna, K.B., R. Ganesh Naik, T.B. Basavaraj, B. Boraiah and N.E. Tyagaraj: Etiology and management of coconut basal stem rot (Ganoderma wilt) in sandy soils of Karnataka. J. Plan. Crops, 37, 26-29 (2009).
Pilotti, C. A., F. R. Sanderson and E. A. B. Aitken: Genetic structure of a population of Ganoderma boninense on oil palm. Plant Pathol., 52, 455-463 (2003).

Pilotti, C. A.M., F.R. Sanderson, E.A.B. Aitken and W. Armistrong: Morphological variation and host range of two Ganoderma species from Papua New Guinea. Mycopathologia, 158, 251-256 (2004).

Rakib, M.R.M., C.F.J. Bong, A. Khairulmazmi and A.S. Idris: Genetic and morphological diversity of Ganoderma species isolated from infected oil palms (Elaeis guineensis). Int. J. Agric. Biol., 16, 691-699 (2014).

Rakotonirainy, M.S, M.L. Cariou, Y. Brygoo and G. Riba: Phylogenetic relationships within the genus Metarhizium based on 28S rRNA sequences and isozyme comparison. Mycol Res., 98, 225-230 (1994).

Sangal, P. M., S.K. Mukherji and B. Singh:A short note on the fungus flora of Nicobar Islands. Indian Fore., 87, 766-767 (1961).

Sharples, A.: Palm diseases in Malaya. Malaya Agricul. J., 16, 313-360 (1928)

Singh, S.K., M.C. Yadav, R.C. Upadhyay, R.D. Shwetkamal and R.P. Tewari: Molecular characterization of specialty mushroom germplasm of the National Mushroom Repository. Mush. Res., 12, 67-78 (2003)

Smith, B.J. and K. Sivasithamparam: Internal transcribed spacer ribosomal DNA sequence of five species of Ganoderma from Australia. Mycol. Res., 104, 943-951 (2000).

Tan, M.K. and L.M. Niessen: Analysis of rDNA ITS sequences to determine genetic relationships among, and provide a basis for simplified diagnosis of Fusarium species causing crown rot and head blight of cereals. Mycol. Res., 107, 811-821 (2003).

Thomsen, L. and A.B. Jensen: Application of nested-PCR technique to resting spores from the Entomophthora muscae species complex: Implications for analyses of host-pathogen population interactions. Mycologia, 94, 794-802 (2002).

Uetake, Y., M. Arakawa, H. Nakamura, T. Akahira, A. Sayama, Cheah LHO, I.O. Okabe and N. Matsumoto: Genetic relationship among violet root rot fungi as revealed by hyphal anastomosis and sequencing of the rDNA ITS regions. Mycol. Res., 106,156-163 (2002).

Wong, L.C., C.F.J. Bong and A.S. Idris: Ganoderma species associated with basal stem rot disease of oil palm. Amer. J. Ppl. Sci., 9, 879$885(2012)$ 